\title{
EN BUSCA DE COHERERCIA Y RESULTADOS: LA POLÍTICA EUROPEA DE VECINDAD EN MOLDAVIA Y GEORGIA
}

\section{Looking for coherence and results: the European neighbourhood Policy in Moldova and Georgia}

\author{
Liz Arnanz \\ Master European Interdisciplinary Studies del College of Europe \\ E-mail: liz.arnanz@gmail.com \\ 0 Autor
}

Los dos Estados más comprometidos con la Política Europea de Vecindad en el Este, Moldavia y Georgia, son un buen ejemplo de que dicha política puede tener un cierto impacto positivo en la sociedad, economía y política de los Estados socios a través de la promoción de reformas democráticas y económicas. No obstante, su impacto hasta ahora ha sido considerablemente limitado cuando se trata de resolver los conflictos secesionistas de estos países: Transnistria en el caso de Moldavia, y Abjasia y Osetia del Sur en el caso de Georgia. A lo largo de este trabajo se intentará defender que la razón de ello reside en el hecho de que los intereses de algunos Estados miembros superan los intereses comunes de la UE, especialmente cuando temen las reacciones coercitivas del Kremlin, debido a la importancia energética de Rusia.

Asociación Oriental, Georgia, Moldavia, Política Europea de Vecindad, Unión Europea Eastern Partnership, Georgia, Moldova, European Neighbourhood Policy, European Union

Q Key mords

Recibido: 13-07-15. Aceptado: 15-08-15

E Resumen

\footnotetext{
The two States that have engaged the most with the European Neighbourhood Policy in the East, Moldova and Georgia, are a good example that this policy could have a certain positive impact on the society, economy and politics of the partner States through the promotion of democratic and economic reforms. Nonetheless, until now, the policy's impact has been significantly limited when dealing with the resolution of the secessionist conflicts of these countries: Transnistria in the case of Moldova, and Abkhazia and South Ossetia in the case of Georgia. Throughout this paper the author will defend that the reason for this lies on the fact that the interests of some Member States weight more than the EU common interests, especially, when they fear Kremlin's coercive reactions, given Russian energy significance.
} 


\section{Introducción}

Desde noviembre de 2013, la prensa no cesa de escribir sobre la crisis en Ucrania. Sin embargo, muchos han olvidado el origen de este conflicto: el momento en el que Viktor Yanukovich rechazó el Acuerdo de Asociación con la Unión Europea (UE) antes de celebrar la Cumbre de Vilnius. Este suceso desembocó en una serie de protestas pro-europeas que acabó con la destitución del presidente Yanukovich. Ante tal situación, la península de Crimea celebró un referéndum ilegal que ha supuesto la anexión de facto de dicho territorio a Rusia. Asimismo, a raíz de ello, las regiones de Donetsk y Lugansk, al este del país, se han proclamado repúblicas independientes de facto con el apoyo de fuerzas rusas.

En definitiva, en un año y medio, Rusia ha vuelto a demostrar su falta de respeto hacia la integridad territorial de sus vecinos tras anexionarse ilegalmente Crimea. Desde entonces, la situación de Ucrania amenaza constantemente con desestabilizar el vecindario a pesar de contar ahora con un nuevo gobierno elegido democráticamente en mayo de 2014, liderado por Petro Poroshenko, quien finalmente ha firmado y ratificado aquel Acuerdo de Asociación que fue objeto de las protestas iniciales (Popescu, 2014; Parlamento Europeo, 2014b).

Pero para entender la crisis en Ucrania, y la situación de la región en los últimos años, es muy importante estudiar y analizar los factores institucionales que engloban a este tipo de acuerdos. Los Acuerdos de Asociación son instrumentos legales impulsados por la Asociación Oriental iniciada en 2009 dentro del marco de la Política Europea de Vecindad (PEV), para diferenciar el vecindario sur del oriental y promover así una mayor integración dentro de la UE a los países de Europa del Este y del Cáucaso Sur: Bielorrusia, Ucrania, Moldavia, Georgia, Azerbaiyán y Armenia (Boonstra \& Shapovalova, 2010). No obstante, la situación de Ucrania ha provocado que en los últimos meses se hable poco de los otros dos países, Moldavia y Georgia, que también han ratificado su Acuerdo de Asociación en 2014 (EurActiv, 2014; RFE/RL, 2014b).

Según el Eastern Partnership Index de 2012, 2013 y 2014, Moldavia y Georgia han sido los países que mejor ejecutaron la PEV dentro del ámbito de la Asociación Oriental, mientras que Ucrania ostenta el tercer puesto (Kvashuk, Solonenko \& Ursu, 2013; Lovitt, 2015). Además, mientras Moldavia y Georgia tienen una población aproximada de 4 millones de habitantes, Ucrania tiene una población de cerca de 46 millones (Martín, 2012, p. 363). Por tanto, no sería muy coherente comparar el impacto de la PEV en Moldavia y Georgia junto con Ucrania si se tiene en cuenta esta diferencia demográfica, además de la inestabilidad actual de este último país, ya que difícilmente se podrá considerar la ejecución de la PEV un éxito en Ucrania hasta que no se estabilice la situación.

Por todo ello, se ha considerado relevante analizar los dos casos más exitosos de la Asociación Oriental para así entender mejor la dinámica del vecindario oriental. A lo largo de este estudio se analizará parte de la literatura sobre la PEV y su impacto en el Este mediante el lanzamiento de la Asociación Oriental en Moldavia y Georgia, junto con el papel que tiene Rusia en la región. Posteriormente, se incluirá una tabla donde se resumen numerosos documentos oficiales de la UE relativos a la PEV en Moldavia y Georgia para entender mejor el contexto institucional de la política desde su creación.

Por último, se realizará un análisis teórico del presente estudio para reforzar la hipótesis de que los Estados orientales más comprometidos con la PEV, Moldavia y Georgia, son un ejemplo de que dicha política puede tener un cierto impacto positivo en la sociedad, economía y política

\section{En un año y} medio, Rusia ha vuelto a demostrar su falta de respeto hacia la integridad temitorial de sus vecinos tras anexionarse ilegalmente Crimea 
de los Estados socios a través de la promoción de reformas democráticas y económicas. Sin embargo, su impacto hasta ahora ha sido considerablemente limitado cuando se trata de resolver los conflictos de estos países. A lo largo de este trabajo se intentará defender que la razón de ello reside en el hecho de que los intereses de algunos Estados miembros superan los intereses comunes de la UE, especialmente cuando temen las reacciones coercitivas del Kremlin, debido a la importancia energética de Rusia.

\section{Una nueva política, para una nueva Europa}

Tras la caída del comunismo en Europa, la UE no podía ofrecer la perspectiva de adhesión a todos sus nuevos vecinos. De este modo su atractivo se reducía de manera considerable y el incentivo por parte de muchos Estados vecinos para transformar sus instituciones a nivel político y económico era menor; es decir, el soft power ${ }^{1}$ de la UE en la región se reducía enormemente. Por tanto, la UE necesitaba ofrecer a su nuevo vecindario oriental una alternativa a la ampliación. Con la intención de reforzar iniciativas previas como los Acuerdos de Colaboración y Cooperación (PCA), se creó una nueva política que aumentase los incentivos a través de una mayor integración en la UE mediante, por ejemplo, la liberación de visados a cambio de reformas políticas, económicas y sociales (Dannreuther, 2006, pp.188-190). Así pues, en 2003, la Comisión Europea publicó Wider Europe donde proponía una nueva política dirigida hacia los vecinos del Sur y del Este y, un año más tarde, el Documento de Estrategia de la PEV salía a la luz estableciendo la nueva política (Comisión Europea, 2003, 2004).

Cabe destacar que el proceso de concepción de la PEV coincidió con la publicación de la primera Estrategia Europea de Seguridad, Una Europa segura en un mundo mejor (Consejo Europeo, 2003). En dicho documento se expresa la necesidad de garantizar la seguridad del vecindario para así fortalecer la seguridad de la comunidad europea. La Estrategia también defiende que la seguridad es necesaria para el desarrollo, ya que los países en conflicto cuentan con un desarrollo económico pobre y con unas instituciones políticas muy débiles. Igualmente, el documento reconoce otras amenazas cada vez más presentes en nuestra sociedad como el terrorismo o la expansión del crimen organizado y de los Estados fallidos, pudiéndose referir también indirectamente a la situación que vive Moldavia con Transnistria o Georgia con Abjasia y Osetia del Sur, territorios que suponen limbos legales para Europa.

En definitiva, dos razones principales impulsaron la creación de la PEV: (1) la necesidad de ofrecer una alternativa a la adhesión a los Estados vecinos y (2) la necesidad de estar rodeados por países estables y prósperos aumentando así la seguridad de la región (Kleenmann, 2010, p. 120).

Además, la PEV surge finalmente para ambos el vecindario sur y oriental con cuatro novedades que aumentan su incidencia. En primer lugar, (1) ofrece mayor integración en la Unión en lo que respecta a las cuatro libertades de movimiento (personas, bienes, servicios y capital); (2) La PEV es más selectiva y el enfoque que le da a cada Estado socio está adaptado a sus circunstancias; igualmente, (3) en términos financieros, la PEV dispone de mayor coherencia y cohesión al con-

1 A lo largo de este trabajo, por hard power se hace referencia a la capacidad que tienen ciertos actores de disuadir a otros a través de medidas coercitivas (militares o no). Por el contrario, el soft power se refiere a la capacidad de persuadir a otros sin necesidad de amenazarlos, es decir, la capacidad de atraerlos. El soft power suele ser una herramienta útil para solucionar problemas desde la raíz, por ejemplo, impulsando valores políticos que promuevan el fortalecimiento de democracias a través de una política exterior de un Estado en una región (Nye, 2011, pp. 20-21, 81-84).
Tras la caída del comunismo, la UE no podía ofrecer la perspectiva de adhesión a todos sus nuevos vecinos. De este modo su atractivo se reducía de manera considerable 
tar con un único instrumento de financiación denominado Instrumento Europeo de Vecindad y Asociación (IEVA) para el periodo 2007-2013; y (4) la financiación de la PEV no solo está mejor distribuida sino que también iba a ser más cuantiosa en comparación con los instrumentos financieros que se dirigían a los países vecinos antes de $2007^{2}$ (Dannreuther, 2006, pp. 190-193).

Asimismo, la PEV se basa en dos conceptos básicos: la condicionalidad positiva — la integración depende del progreso del Estado socio — y la diferenciación de la asociación — la intensidad de la relación con la UE dependerá de los valores que comparta cada socio con la Unión- (Kleenmann, 2010, p. 125). Por ello, la UE es muchas veces considerada como una potencia normativa, es decir, un actor que promueve en el exterior sus normas y valores (Manners, 2002). Por tanto, la PEV puede considerarse como una alternativa a la ampliación y otra forma de extender el poder normativo de la UE. Sin embargo, al no ofrecer la posibilidad de adhesión, esta política pierde gran parte de legitimidad y capacidad (Haukkala, 2008, pp. 1604, 1611).

No obstante, hay un aspecto que preocupa a la UE: su dependencia energética con Rusia. La PEV podría poner en peligro sus relaciones (y sobre todo, sus intereses energéticos) con el Kremlin (Dannreuther, 2006, pp. 194-196). Sin embargo, se puede decir que, en parte, la PEV ha aumentado la coherencia de la política exterior europea en su vecindario. Aunque también la competencia interna que hay entre los Estados miembros que prefieren priorizar los países mediterráneos y los que favorecen el vecindario oriental (o Rusia) no deja de suponer un obstáculo para la correcta implementación de la PEV (Herranz, 2007, p. 273). Pero si la PEV carece de coherencia y no ofrece suficiente incentivo, ¿por qué Moldavia y Georgia han decidido ratificar respectivamente un Acuerdo de Asociación con la UE?

\subsection{Una nueva iniciativa, para una Europa oriental}

En mayo de 2009, la Asociación Oriental se lanzó durante su primera Cumbre en Praga tras una propuesta previa de Polonia y Suecia para definir una PEV más orientada hacia esta región y diferenciarla así de las políticas dirigidas hacia los países del Mediterráneo también incluidos en la PEV (Boonstra y Shapovalova, 2010). La rápida creación de esta iniciativa podría interpretarse como una reacción a la guerra de 2008 entre Georgia y Rusia (Pop, 2009, p. 30).

La Asociación Oriental ofrece la posibilidad de firmar Acuerdos de Asociación, dichos documentos incluyen acuerdos de libre comercio extremadamente importantes —Zona de Libre Comercio de alcance Amplio y Profundo (DCFTA) — si se tiene en cuenta que una gran parte de las exportaciones de Moldavia y Georgia van dirigidas a la UE (Kleenmann, 2010, p. 122). Asimismo, la asociación incluye también la posibilidad de firmar acuerdos para la liberalización de visados (Boonstra y Shapovalova, 2010, p. 3). En efecto, en febrero de 2014, el Parlamento Europeo aprobó la liberalización del régimen de visados que tenía con Moldavia (Parlamento Europeo, 2014a).

En cuanto a la iniciativa en sí, desde el punto de vista de la UE, los Acuerdos de Asociación cuentan con una enorme mejoría respecto a los Planes de Acción de la PEV: los acuerdos pue-

2 Antes del Marco Financiero Plurianual (MFP) 2007-2013 (el IEVA comprendía 11.181 millones de euros), la PEV se financiaba con los dos instrumentos empleados anteriormente para la cooperación con países del Mediterráneo, MEDA, y con el espacio ex-soviético, TACIS. Para el nuevo MFP 2014-2020, el IEVA se ha convertido en el Instrumento Europeo de Vecindad (IEV) con 15.433 millones de euros. Véase Parlamento Europeo y Consejo de la UE (2006); Comisión Europea (2013d); Kleenmann (2010, p. 123).

\section{La UE es muchas} veces considerada como una potencia normativa, es decir, un actor que promueve en el exterior sus normas y valores 
den ser «legalmente vinculantes y cuentan con un sistema de monitoreo y evaluación fuerte que incrementa la posibilidad de una implementación exitosa» (Boonstra \& Shapovalova, 2010, p. 3). No obstante, la gran novedad de la Asociación Oriental es su dimensión regional que impulsa una mayor cooperación y un diálogo político multilateral a través de, por ejemplo, las cumbres celebradas cada dos años (Boonstra \& Shapovalova, 2010, p. 6).

\section{2. ¿Una nueva amenaza para Rusia?}

La PEV se caracteriza por ser una política estratégica no coercitiva, ya que no conlleva sanciones, sino que ofrece incentivos acordados por mutuo acuerdo e interés. Es decir, la UE ha querido promocionar la PEV como una política exterior ética, un juego de suma positiva donde ambas partes salen ganando (Barbé \& Johannes-Nogués, 2008, pp. 81-82). Sin embargo, la PEV difícilmente será vista como una política de suma positiva para todos por parte del Kremlin. No obstante, esta política no debería interpretarse como una iniciativa anti-rusa, sino como la manera que tiene la UE para transmitir su modo de hacer las cosas: con democracia (Wilson y Popescu, 2009, p. 330). De hecho, el documento inicial Wider Europe incluía a Rusia, quien decidió rechazar la propuesta al no querer verse al mismo nivel que los otros Estados socios y así reafirmarse como potencia en el vecindario común (Comisión Europea, 2003; Cámara, 2008, p. 90).

Por tanto, Rusia lucha por seguir siendo el país de referencia para gran parte de los países exsoviéticos mediante, por ejemplo, la Unión Económica Eurasiática entre Rusia, Bielorrusia, Kazajstán, Armenia y, desde agosto de 2015, Kirguizistán (Leonard, 2015). Sin embargo, la integración con Rusia parece limitada, mientras que tampoco se sabe si es compatible con una mayor integración en la UE. De hecho, el establecimiento tan rápido y repentino de dicha iniciativa parece una reacción ante el lanzamiento de la Asociación Oriental: la Unión Económica podría considerarse como una alternativa a las DCFTA. Pero en 2008, las relaciones de Rusia empeoraron no solo con Occidente por la guerra con Georgia, sino que también con su vecindario al reconocer la independencia de Abjasia y de Osetia de Sur y, por tanto, al ignorar la integridad territorial de una república ex-soviética, Georgia (Zagorski, 2012).

Sin embargo, la UE continúa enfrentándose al dilema de cómo compaginar sus relaciones con el vecindario oriental con sus relaciones con Rusia. Una PEV muy fuerte podría ser considerada como una contención de Rusia (Fischer, 2010), un equilibrio de poder contra la influencia rusa. Por otro lado, la PEV también carece de un incentivo muy importante como ya se ha explicado. Al no ofrecer la perspectiva de adhesión, puede que los Estados socios acaben vinculándose más con Rusia al ofrecer más resultados a corto plazo (Dannreuther, 2006, pp. 199-200; Zagorski, 2012). Así pues, parece que la lucha por influenciar a estos Estados es comparable a la dinámica de los mercados: la fuerza de la oferta y la demanda. Mientras la UE está inmersa en su crisis económica, Rusia reclama su papel en la región a través de una política rusa de vecindad informal, con más resultados a corto plazo, mejor financiada y que no solo incluye soft power, sino que también hard power (Wilson y Popescu, 2009, pp. 317-318).

Uno de los elementos del soft power ruso reside en la Iglesia Ortodoxa Rusa que tiene una fuerte influencia en Estados como Moldavia. Otro elemento es el apoyo de Rusia a ciertas ONGs en regiones con gran autonomía e incluso con aspiraciones secesionistas como puede ser Gagauzia en Moldavia. No obstante, Rusia destaca por su uso de hard power, como lo demuestra (1) su intervención militar en Georgia o su presencia militar en Transnistria, (2) la amenaza de
LaPEV se caracteriza por ser una política estratégica no coercitiva, ya que no conlleva sanciones, sino que ofrece incentivos acordados por mutuo acuerdo e interés 
aumentar los precios o de cortar el suministro de gas a Ucrania o Moldavia, o (3) el establecimiento de embargos sobre el vino de Moldavia o de Georgia, entre otras medidas coercitivas. Sin embargo, muchas de estas represalias contrarrestan los esfuerzos de Rusia por emplear soft power (Wilson \& Popescu, 2009, pp. 319-323). En definitiva, la PEV no es completamente criticable, constituye dos grandes y raras ventajas que, por ejemplo, no suele cumplir Rusia: «continuidad política y consistencia» (Soler i Lecha \& Viilup, 2011, p. 5).

\section{El caso de Moldavia y Georgia}

\subsection{Moldavia y su contexto}

Moldavia se enfrenta a muchos problemas que desestabilizan su dinámica política, entre ellos destacan el conflicto de Transnistria, una élite política dividida, la ausencia de reformas consistentes y de un Estado de derecho en funcionamiento (Ventila, 2010, p. 5). Por si fuera poco, desde su independencia en 1991, Moldavia sigue siendo el Estado más pobre de Europa, con una economía precaria y un sistema político todavía inestable (The Economist, 2010). Además, en el momento de la independencia, Moldavia tuvo que decidir si orientarse hacia Rumanía, debido a sus lazos históricos y culturales, o hacia Rusia, debido a su importante comunidad rusófona. Por consiguiente, los primeros años de independencia de Moldavia se centraron más en el debate identitario que en las reformas necesarias (Ventila, 2010, pp. 1-2).

En las elecciones legislativas de abril de 2009, el Partido Comunista de la República de Moldavia (PCRM), quien tiene una posición más bien amistosa hacia Rusia, volvió a ganar por tercera vez. Pocos días después, la insatisfacción de los jóvenes con los resultados de las elecciones y las acusaciones de fraude electoral provocaron fuertes protestas de carácter pro-occidental que acabaron violentamente reprimidas por las autoridades. Pero el Tribunal Constitucional reconoció la legalidad de las elecciones; aunque en julio de 2009 se volvieron a celebrar elecciones ya que el nombramiento del presidente requiere el apoyo de 61 miembros de los 101 diputados que componen el Parlamento moldavo y el poder legislativo no se puso de acuerdo en dos ocasiones. En estas elecciones, la participación fue mayor y el resultado fue similar: el PCRM obtuvo la mayoría de los votos (Ventila, 2010, pp. 3-4; Deyfrus, 2009).

No obstante, en esta ocasión, la mayor parte de la oposición pro-europea decidió formar una coalición obteniendo mayoría: la Alianza para la Integración Europea. Pero la coalición tampoco fue capaz de designar un presidente demostrándose así su fragilidad. Aun así no se volvieron a celebrar elecciones ya que el Parlamento no puede ser disuelto dos veces en un mismo año (Ventila, 2010, p. 4). Cuando en marzo de 2012 se eligió finalmente al actual presidente del país, Nicolae Timofti, en diciembre de 2012, un hombre murió de un disparo durante una cacería en grupo que reunía supuestamente a miembros de la élite política moldava asociados a uno de los partidos de la alianza. El fiscal general, nombrado por dicho partido, intentó cubrir el caso y cuando este salió a la luz, el gobierno se disolvió y los partidos pro-europeos tuvieron que establecer una nueva coalición. Sin embargo, el nuevo primer ministro desde abril de 2013 hasta febrero de 2015, Iurie Leanca, volvió a estabilizar el panorama político de Moldavia (EU ISS, 2013; Trifon, 2013, p. 14) y, en 2013, el país se comprometió exitosamente a firmar el Acuerdo de Asociación (Comisión Europea, 2013c).

Todo ello, a pesar de que Rusia estuvo durante el año 2013 tratando de disuadir al pequeño Estado para que no firmase el acuerdo mediante la imposición de un embargo sobre su vino en 
septiembre —aunque Rusia alegaba que se debía a impurezas en el vino- (Solash, 2013). De hecho, a principios de septiembre de 2013, el viceprimer ministro de Rusia —y también Representante Especial de Rusia en Transnistria- Dmitri Rogozin estuvo de visita en Moldavia y dijo que la firma de un acuerdo con la UE sería una costosa equivocación por parte de Moldavia, mientras recordaba que el pequeño Estado depende completamente de Rusia a nivel energético y amenazaba con frenar la importante inmigración que hay de Moldavia a Rusia (Dempsey, 2013).

Además, según Niemann y Wekker (2010, pp. 27-28), los pocas reformas normativas realizadas por Moldavia son gracias a la UE, por ejemplo, la condicionalidad positiva de la PEV ha hecho que Moldavia ratifique tratados internacionales como el de la Convención de Naciones Unidas contra la Corrupción. Por tanto, Moldavia puede considerarse un ejemplo de que las escasos incentivos de la PEV han sido suficientes para impulsar considerables reformas. Ya el Informe de Progreso en Moldavia de 2006 destacaba numerosos cambios impulsados por Moldavia en acorde con su Plan de Acción en asuntos como la corrupción, la inmigración y la abolición de la pena de muerte (Sasse, 2008, p. 313).

Sin embargo, como lo muestra la crisis política de 2013, es demasiado pronto para asegurar que Moldavia es un caso exitoso de la PEV. Las elecciones legislativas del 30 de noviembre de 2014 se desarrollaron bajo mucha tensión entre partidos pro-europeos y partidos pro-rusos. Los primeros ganaron un pequeña mayoría manteniendo las mismas autoridades políticas en el poder; sin embargo, el partido más votado fue el nuevo Partido Socialista de enfoque pro-ruso. Una vez más los resultados de las elecciones mostraron la polarización de las élites políticas y de la sociedad moldava (The Economist, 2014). De hecho la ratificación del Acuerdo de Asociación en julio de 2014 en el Parlamento moldavo salió adelante con una modesta mayoría de votos a favor, mientras que la ratificación en Georgia tuvo un apoyo político unánime (EurActiv, 2014; RFE/RL, 2014b).

Con el nuevo gobierno desde febrero de 2015 de Chiril Gaburici, elegido en parte con el apoyo del PCRM tras la elecciones de noviembre de 2014 al no haber mayoría en el parlamento, ha habido temores de que se muestre hostil hacia ciertas iniciativas europeas (Ursu \& Coalson, 2015). Pero Gaburici todavía no ha tenido tiempo de demostrar su compromiso con la UE, dimitió en junio de este año debido a acusaciones de haber falsificado sus diplomas. Desde finales de julio, el nuevo primer ministro es Valeriu Strelet, aunque puede que no por mucho tiempo, hay riesgo de que se adelanten las elecciones legislativas a 2016 (Călugăreanu, 2015).”

Mientras tanto, en lo que respecta a la resolución del conflicto con Transnistria, la UE ha sido poco eficiente o, mejor dicho, poco coherente. Por ejemplo, en dos ocasiones (2003 y 2006), la UE intentó contribuir con personal de mantenimiento de paz en dicho territorio; en el primer intento, Rusia se opuso; y en el segundo, fueron varios Estados miembros quienes esta vez rechazaron la propuesta: España, Portugal, Francia, Italia, Grecia, Chipre, Eslovaquia, Alemania y Finlandia (Wilson \& Popescu, 2009, p. 326).

\subsubsection{El conflicto en Transnistria}

La parte más industrializada de Moldavia se encuentra precisamente en Transnistria, la cual representa el $17 \%$ de la población de Moldavia mientras que produce el 35\% del PIB, lo que supone una gran pérdida para Moldavia (Izquierdo, 2014, p. 2; Deyfrus, 2009). En efecto, como defiende Popescu (2005), la base de este conflicto es económica y, por tanto, se podría resolver si Moldavia mejorase su atractivo económico y eliminase los intereses económicos que hacen que a los transnistrianos les convenga mantener este conflicto. Como dijo el antiguo ministro de facto
Como lo muestra la crisis política de 2013, es demasiado pronto para asegurar que Moldavia es un caso exitoso de la PEV 
de Asuntos Exteriores de Transnistria, «si Moldavia fuese como Suiza, todos firmaríamos mañana mismo para reunificarnos» ${ }^{3}$ (cit. en O’Neill, 2009). En cuanto a aspectos demográficos, Transnistria está compuesta por 500.000 personas, de las cuales el 38\% son étnicamente moldavas, 28\% rusas y 26\% ucranianas; y la gran mayoría son cristianos ortodoxos (Popescu, 2005, p. 15).

Por lo tanto, no se puede decir que sea un conflicto étnico ni religioso, sino más bien económico y de desacuerdo político: tras la independencia de Moldavia, Transnistria quería permanecer en la URSS y es así como se inició una breve guerra en 1992 con el apoyo de Rusia que acabó con la intervención de ejército decimocuarto ruso, el cual ha permanecido allí desde entonces (Popescu, 2005, p. 15). El conflicto armado finalizó con un acuerdo entre Rusia y Moldavia a través del cual este último debía retirar sus tropas del territorio y Rusia mantendría una misión de mantenimiento de paz (Huff, 2011, pp. 27). Asimismo, la OSCE siempre ha estado involucrada en el conflicto de Transnistria a través de su misión y con el inicio de negociaciones de carácter político entre Moldavia y Transnistria donde Rusia, Ucrania y la OSCE participan como mediadores (five-sided format) (Popescu, 2005, pp. 16-17). En 2005, los Estados Unidos y la UE se unieron a dichas negociaciones como observadores $(5+2$ format), pero las negociaciones permanecieron congeladas durante años hasta que en 2011 se retomaron, aunque sin grandes resultados por el momento (Wolff, 2012, pp. 41-42).

No obstante, Rusia siempre ha favorecido las negociaciones en formato 2+1 (Moldavia, Transnistria y Rusia) para así no resolver esta disputa evitando que Moldavia se adhiera a la UE u OTAN (Huff, 2011, p. 28). Ante este contexto, según O’Neill (2009), antiguo embajador y jefe de la Misión de la OSCE en Moldavia (2006-2008), existen cinco posibles escenarios para el futuro: (1) Transnistria y Moldova se reúnen, pero la primera mantiene una cierta autonomía; (2) Transnistria se independiza por completo, aunque no es seguro que sea internacionalmente reconocida ni que pueda subsistir sin ayuda económica de otro Estado; (3) Transnistria acaba anexionándose a Rusia o (4) a Ucrania; (5) la situación continúa como está, statu quo.

Mientras, la UE ha apoyado a Moldavia más bien en términos diplomáticos. En 2003, la UE decidió prohibir a los líderes de Transnistria el derecho a viajar a la UE —aunque solo cuando así lo hicieron los Estados Unidos-. En 2005, la UE nombró a un Representante Especial para Moldavia e inauguró una delegación en Chisinau (Niemann \& Wekker, 2010, p. 29; Sasse, 2008, p. 312). Sin embargo, Moldavia es un buen ejemplo de cómo la PEV ha impulsado la cooperación regional entre sus vecinos para aumentar la estabilidad. En 2005, Ucrania y Moldavia acordaron con la UE una Misión de asistencia fronteriza (EUBAM). Los objetivos principales de la EUBAM eran compartir la experiencia europea para proteger las fronteras de tráficos ilícitos y aumentar la cooperación aduanera entre Moldavia y Ucrania (Huff, 2011, p. 20). En efecto, a través de esta misión, Ucrania se comprometió a solo aceptar productos de Transnistria si llevaban el sello de Moldavia y, para ello, Moldavia facilitaría el acceso a dichos sellos a las empresas transnistrianas (Sasse, 2008, p. 312), lo que ilegitima a Transnistria, dándole a entender que no puede tener su propio comercio sin pasar antes por las autoridades moldavas.

\subsubsection{Las relaciones con Rumanía}

En su plan de política exterior de 1998 a 2002, Moldavia especificaba como objetivo estratégico su integración en la UE. Este objetivo probablemente incrementó tras la adhesión de Rumanía

\section{En su plan de política exterior de 1998 a 2002, Moldavia especificaba como objetivo estratégico su integración en la UE}


a la UE en 2007 (Sasse, 2008, p. 311 ). En efecto, el lazo cultural con Rumanía es muy fuerte debido a su historia común, la actual República de Moldavia era una parte del histórico Principiado de Moldavia (región rumana) conocida como Besarabia que el imperio ruso anexionó en 1812. Asimismo, el $80 \%$ de la población habla rumano, ya que la lengua de los moldavos es prácticamente idéntica (Deyfrus, 2009). La relación histórica, cultural e identitaria entre Moldavia y Rumanía es tan fuerte que Traian Basescu, antiguo presidente de Rumanía, cambió la ley de naturalización para permitir que casi un millón de moldavos puedan acceder a la nacionalidad rumana (O’Neill, 2009).

Mejor aún, en 2013 se anunció que Rumanía iniciaría la construcción de un gaseoducto con un coste de 28 millones de euros (en parte financiado por la UE) entre las ciudades de Iasi y Ungheni conectando el pequeño Estado a la red europea de gas (Comisión Europea, 2013a). El gaseoducto fue inaugurado en agosto de 2014, aunque sin recibir suministro ya que la empresa encargada de la distribución de gas, Moldovagaz, estaba retrasando la importación de gas desde Rumanía, lo que no es de extrañar ya que la empresa está controlada por Gazprom. Sin embargo, Vestmoldtransgaz recibió la licencia para el transporte de gas en enero de 2015 y la importación de gas desde Rumanía empezó en marzo. Por otro lado, el gas de momento solo llega a una pequeña parte de Moldavia, por eso se está construyendo una prolongación hasta Chisinau que llevará años (Barbarosie y Coalson, 2014; Moldpres, 2015a, 2015b)”. Por tanto, el proyecto aún necesita más tiempo y financiación, aunque es extremadamente importante para Moldavia, ya que podría dejar de depender de Rusia en gas, algo crucial si se tiene en cuenta que (1) dos tercios de la demanda de gas de Moldavia es consumida por Transnistria, (2) la deuda que Transnistria tiene con Rusia por el consumo de gas es mucho mayor que la del propio Estado moldavo y (3) Rusia se dirige a Chisinau y no a Tiraspol para cobrar la deuda de Transnistria (Trifon, 2013, p. 13).

\subsection{Georgia y su contexto}

Tras la Revolución Rosa de 2003, se inició un nuevo régimen encabezado por Mikheil Saakashvili, quien durante años lideró un gobierno reformista pro-occidental, pero al mismo tiempo reprimió a la oposición de manera autoritaria (Ditrych, 2013). No obstante, su lucha contra la corrupción en dicho país dio su fruto cuadruplicándose así el presupuesto estatal desde que Saakashvili había asumido el poder (Jégo, 2014, p. 130). Pero aunque el gobierno de Saakhashvili haya modernizado el Estado, todavía quedan por hacer muchas reformas en lo que respecta a la democracia. Además, parece que la lucha contra la corrupción fue selectiva, ya que la independencia judicial es aún escasa y sigue habiendo un sentimiento de impunidad (Leonard \& Grant, 2005, pp. 2-3). En cuanto a los territorios secesionistas, la actitud de Saakashvili fue mucho más proactiva que la de su predecesor E. Shevardnadze. El presidente intentó reforzar el control de fronteras de ambos territorios separatistas, pero también tuvo otras iniciativas constructivas como ofrecer mayor autonomía a las dos regiones y legalizar la doble nacionalidad (Leonard \& Grant, 2005, p. 5).

Sin embargo, en octubre de 2012, las elecciones legislativas de Georgia dieron por vencedor a una nueva coalición, Sueño Georgiano, compuesta de numerosos y diversos partidos de la oposición y liderado por un multimillonario, Bidzina Ivanishvili, cuya fortuna procede de negocios en Rusia. La cohabitación con el ya debilitado Saakashvili no fue fácil en absoluto, sobre todo si se tiene en cuenta que la visión política de la coalición es ambigua y parece más bien centrada en vengarse
En 2012, las elecciones de Georgia dieron por vencedor a Sueño Georgiano, liderado por un multimillonario cuya fortuna procede de negocios en Rusia 
del gobierno anterior. Por ejemplo, Ivanshvili insistió en aprobar una enmienda constitucional que redujese el poder del presidente. Debido al temor que tenía Saakashvili de que el nuevo gobierno pudiera acercarse a Rusia, accedió a votar a favor de esta enmienda a cambio de que hicieran una declaración conjunta en la cual se reafirmase la prioridad de Georgia para integrarse en las estructuras de la UE y OTAN. Igualmente, existen temores de que la justicia de Georgia esté siendo cada vez más selectiva; al parecer el nuevo gobierno está obsesionado con detener y sentenciar a personas relacionadas con el partido de Saakashvili (Ditrych, 2013). Pero la cohabitación entre Saakhashvili y Ivanishvili finalizó tras las elecciones nacionales de 2013: el Sueño Georgiano volvió a ganar y se nombró como presidente a Georgi Margvelashvili y como primer ministro al Irakli Garibashvili, quienes también parecen estar enfrentados demostrándose también la fragilidad política del nuevo Sueño Georgiano (Coalson, 2014).

No obstante, es esencial que la UE permanezca presente en la región ya que tiene varios intereses directos en Georgia: (1) que los objetivos de la Revolución Rosa se cumplan para así construir una democracia fuerte en Georgia, la cual sería la primera democracia consolidada en el Cáucaso Sur; (2) que la región permanezca estable ya que está próxima a la cada vez más amplia UE (ahora comparten frontera marítima); (3) que el oleoducto (Baku-Tbilisi-Ceyhan) y el gaseoducto (Baku-Tbilisi-Erzurum), al igual que otros proyectos en construcción, que pasan por Georgia desde el Mar Caspio no peligren, ya que abastecen en parte a la UE reduciendo su dependencia en Rusia; (4) que no haya una guerra en el continente; y (5) que Georgia no acoja terroristas extremistas propagándose sus actividades por la región del Mar Negro (Lynch, 2006, pp. 66-68).

\subsubsection{El papel de la UE}

En 2003, la UE designó un Representante Especial para todo el Cáucaso Sur con el fin más bien de apoyar los mecanismos de resolución de los conflictos que de intervenir en ellos. Cuando la Misión de observación de las fronteras de la OSCE en Georgia se desintegró en 2004 debido a que Rusia la vetó, Tbilisi sugirió a la UE que cogieran el relevo. La UE planteó cuatro posibilidades: (1) substituir la misión de la OSCE por completo, (2) apoyar una misión similar, (3) lanzar una misión de entrenamiento para las autoridades fronterizas o (4) enviar tres expertos para aconsejar reformas. Por miedo a enfadar a Rusia, la UE acabó decidiendo implementar la opción más pobre de todas: mandó a tres expertos, aunque posteriormente se enviaron más (Popescu, 2007, pp. 10-15).

Por otro lado, como reacción a la Revolución Rosa, entre julio de 2004 y julio 2005, la UE lanzó la Misión de la UE para el Estado de Derecho en Georgia (EUJUST Themis) con el objetivo principal de cambiar el sistema judicial en un único año, un objetivo bastante ambicioso. La misión estaba compuesta por un equipo de ocho expertos encargados de reformar el sistema judicial penal del país (incluida la abolición de la pena de muerte) y de aumentar la seguridad promoviendo el control de fronteras y la cooperación regional (Popescu, 2011, p. 192; Huff, 2011, p. 18).

En octubre de 2008, como respuesta a la guerra entre Rusia y Georgia en agosto de 2008, la UE lanzó la Misión de Observación de la UE (EUMM) en Georgia y con el fin de controlar la retirada de las tropas rusas y georgianas, y el respeto de las minorías y de los derechos humanos en general (Popescu, 2011, p. 194). No obstante, el éxito de EUMM es extremadamente limitado: las autoridades de Rusia, Abjasia y Osetia del Sur le han denegado constantemente el acceso a las zonas en conflicto (Huff, 2011, pp. 22-23). Además, esta reciente presencia en la región 
debe tratarse con cuidado: la misión debe estabilizar la situación sin llegar a legitimarla (Freira \& Simao, 2013, p. 18). Por ejemplo, la UE lanzó a finales de 2009 una Política de Compromiso y No-Reconocimiento para Abjasia y Osetia de Sur, de este modo puede reforzar relaciones con ambos territorios sin negar la integridad territorial de Georgia (Huff, 2011, p. 33).

\subsubsection{Los dos conflictos secesionistas: Abjasia y Osetia del Sur}

El conflicto en Osetia del Sur es menos importante en cuanto a magnitud. En 1989, la población de esta región era de solo aproximadamente 100.000 habitantes, de los cuales un 66\% eran osetas y un 29\%, georgianos. A partir de ese año, Osetia del Sur solicitaba ser más que una región autónoma de Georgia: una república autónoma como la de Osetia del Norte en Rusia. Pero en pleno auge del nacionalismo georgiano, durante la caída de la URSS, Georgia decidió retirarle la autonomía que ya tenía lo que inició un conflicto armado (Lynch, 2006, p. 19). Así se inició una guerra civil entre Georgia y Osetia del Sur que finalizó en 1992 con un acuerdo de paz mediado por la OSCE quien estableció desde entonces una misión de observación, mientras que Rusia también estableció una misión de mantenimiento de paz (International Crisis Group, 2007, p. 1).

En el caso de Abjasia, la guerra duró hasta 1994 y fue la ONU quien estableció una misión de observación (UNOMIG) junto con otra misión de mantenimiento de paz rusa (Huff, 2011, p. 32). La guerra de Abjasia provocó el desplazamiento de aproximadamente 280.000 personas, mientras que la de Osetia del Sur (1992) causó menos desplazados internos y eran mayoritariamente osetas que decidieron pasarse a Osetia del Norte (Lynch, 2006, pp. 18-20). Por tanto, en término demográficos, Abjasia ha cambiado drásticamente. Según el censo de 1989 de la URSS y el censo de 2011 de Abjasia, en 1989 había aproximadamente un 18\% de abjasios y un $46 \%$ de georgianos en Abjasia; mientras que en 2011, el porcentaje de abjasios aumentó hasta un $51 \%$ y el de georgianos se redujo hasta un $18 \%$ (Zhemukhov, 2012).

Asimismo, en 2009, tras la guerra, Rusia vetó las misiones de la OSCE y de la ONU, lo que provocó que la única misión vigente en el país sea ahora la EUMM (Huff, 2011, pp. 32-33). Mientras tanto, Rusia sigue incrementando su presencia en Georgia y está construyendo una valla a lo largo de la frontera que separa Osetia del Sur con el resto de Georgia, una acción inaceptable ya que restringe a los georgianos el acceso a ciertos recursos básicos como el agua (Ditrych, 2013). Ahora pues, existen cinco escenarios posibles para los conflictos de Abjasia y Osetia del Sur: (1) reconocer su respectiva soberanía internacionalmente; (2) atacar y destruir su gobierno como hizo Rusia en Chechenia en 1999 — una opción en absoluto preferible vista la guerra entre Georgia y Rusia en 2008-; (3) reintegrar los territorios en una Georgia federal a la fuerza o (4) pacíficamente; o (5) mantener el statu quo (Coppietiers, 2007, pp. 9-12).

\subsection{La política europea de vecindad en Moldavia y Georgia}

A continuación, se incluye resumido en una tabla un estudio de la legislación y de las comunicaciones oficiales que se han considerado más relevantes en relación con la PEV en Moldavia y Georgia desde su creación hasta la firma de los Acuerdos de Asociación.
La guerra civil entre Georgia y Osetia del Sur finalizó en 1992 con un acuerdo de paz mediado por la OSCE, que estableció una misión de observación 
Tabla. Documentos de la PEV relevantes para Moldavia y Georgia ${ }^{4}$

\begin{tabular}{|c|c|c|}
\hline Legislación & MOLDAVIA & GEORGIA \\
\hline \multirow{4}{*}{ Wider Europe, 2003} & $\begin{array}{l}\text { Comunicación de la Comisión Europea para Parlamento Europeo y } \\
\text { Consejo de la UE. }\end{array}$ & \multirow{4}{*}{$\begin{array}{l}\text { No incluye a los países del Cáucaso Sur (Georgia, } \\
\text { Azerbaiyán y Armenia) }\end{array}$} \\
\hline & Incluye a Rusia. & \\
\hline & $\begin{array}{l}\text { Con la nueva ampliación de 2004: } \\
\text { (1) necesidad de una estrategia en relación con los nuevos vecinos } \\
\text { de la UE para no crear divisiones e inestabilidad en la región; } \\
\text { (2) necesidad de una política que no incluya la posibilidad de } \\
\text { adhesión a corto y medio plazo. }\end{array}$ & \\
\hline & $\begin{array}{l}\text { Proposición de: } \\
\text { (1) mayor integración en UE y cooperación; } \\
\text { (2) establecimiento de Planes de Acción; } \\
\text { (3) condicionalidad (según cumplimiento de reformas); } \\
\text { (4) diferenciación. }\end{array}$ & \\
\hline \multirow{3}{*}{ Documento de Estrategia, 2004} & \multicolumn{2}{|c|}{$\begin{array}{l}\text { Rusia ya no aparece y considera a los tres países del Cáucaso Sur tras publicación de la Estrategia Europea de Seguridad } \\
\text { en } 2003 .\end{array}$} \\
\hline & \multicolumn{2}{|c|}{$\begin{array}{l}\text { Planes de Acción bilaterales diferentes y elaborados según principios comunes. La Comisión Europea es encargada de } \\
\text { controlar el progreso en cada país. }\end{array}$} \\
\hline & \multicolumn{2}{|c|}{$\begin{array}{l}\text { Conceptos clave: (1) diferenciación, (2) titularidad compartida, (3) valor añadido: de simple cooperación a mayor integración } \\
\text { en la UE y otros incentivos. }\end{array}$} \\
\hline \multirow[b]{4}{*}{ Planes de Acción } & 2005 & 2006 \\
\hline & \multicolumn{2}{|c|}{$\begin{array}{l}\text { Promover más que una simple cooperación bilateral: mayor integración en las estructuras de la UE. } \\
\text { Continuar apoyo a la resolución de los conflictos secesionistas. }\end{array}$} \\
\hline & \multicolumn{2}{|c|}{ Prioridades principales } \\
\hline & $\begin{array}{l}\text { 1) Transnistria } \\
\text { 2) Estado de Derecho } \\
\text { 3) Libertad de expresión y de los medios de comunicación } \\
\text { 4) Sistema judicial y capacidad administrativa } \\
\text { 5) Reducción de la pobreza } \\
\text { 6) Lucha contra la corrupción } \\
\text { 7) Control de fronteras } \\
\text { 8) Comercio: origen de los productos } \\
\text { 9) Lucha contra el crimen organizado } \\
\text { 10) Control de migraciones }\end{array}$ & $\begin{array}{l}\text { 1) Estado de Derecho y sistema judicial } \\
\text { 2) Perspectivas para la economía e inversión y lucha } \\
\text { contra la corrupción } \\
\text { 3) Reducción de la pobreza y cohesión social } \\
\text { 4) Cooperación en asuntos de seguridad, fronteras y } \\
\text { justicia } \\
\text { 5) Cooperación regional } \\
\text { 6) Conflictos secesionistas } \\
\text { 7) Cooperación en política exterior y de seguridad } \\
\text { 8) Transporte y energía }\end{array}$ \\
\hline \multirow{3}{*}{$1^{\text {a }}$ Reforma, 2006} & \multicolumn{2}{|l|}{$\begin{array}{l}\text { Puntos fuertes: } \\
\text { (1) integración en la UE, } \\
\text { (2) titularidad compartida, } \\
\text { (3) Planes de Acción concretos, y } \\
\text { (4) IEVA de } 2007 \text { a } 2013 .\end{array}$} \\
\hline & \multicolumn{2}{|l|}{$\begin{array}{l}\text { Puntos flojos: } \\
\text { (1) integración comercial, } \\
\text { (2) movilidad de las personas, y } \\
\text { (3) conflictos congelados. }\end{array}$} \\
\hline & \multicolumn{2}{|c|}{$\begin{array}{l}\text { Reformas: } \\
\text { (1) negociar DCFTA, } \\
\text { (2) facilitar régimen de visados, } \\
\text { (3) aumentar cooperación política y regional (especialmente en la región del Mar Negro). }\end{array}$} \\
\hline IEVA 2007-2013 & \multicolumn{2}{|l|}{ General $=11.181$ millones de EUR } \\
\hline \multirow{2}{*}{$\begin{array}{l}\text { Programa Indicativo Nacional (PIN) } \\
2007-2010\end{array}$} & 209,7 millones de EUR & 120,4 millones de EUR \\
\hline & $\begin{array}{l}40-60 \% \text { destinado a promover la reducción de pobreza y el } \\
\text { crecimiento económico }\end{array}$ & $\begin{array}{l}1 / 3 \text { destinado a promover la reducción de pobreza y } \\
\text { las reformas sociales }\end{array}$ \\
\hline
\end{tabular}

4 Tabla elaborada por el autor del trabajo mediante el resumen de las siguientes fuentes oficiales de la UE: Comisión Europea, 2003, 2004, 2005, 2006a, 2006b, 2008a, 2008b, 2011, 2013b, 2013c, 2013d, 2014. Comisión Europea y Alto Representante de la Unión para Asuntos Exteriores y Política de Seguridad, 2011, 2013a, 2013b. Comisión Europea y Dirección General de Relaciones Exteriores, 2007a, 2007b, 2010a, 2010b. Consejo de la Unión Europea, 2009, 201 1, 2013, 2015b. Parlamento Europeo, 2014a. Parlamento Europeo y Consejo de la Unión Europea, 2006. 


\begin{tabular}{|c|c|c|}
\hline Legislación & MOLDAVIA & GEOREIA \\
\hline & \multicolumn{2}{|l|}{ Evoluciones destacables } \\
\hline Informes de progreso en 2007 (2008) & $\begin{array}{l}\uparrow \text { Elecciones locales } \\
\uparrow \text { Reforma parlamentaria } \\
\uparrow \text { Sistema judicial } \\
\uparrow \text { Lucha contra la corrupción } \\
\uparrow \text { Prevención del tráfico de personas y de la tortura } \\
\uparrow \text { Libertad de asociación y de los medios de comunicación } \\
\uparrow \text { Lucha contra la discriminación } \\
\uparrow \text { Apoyo EUBAM } \\
\downarrow \text { Bloqueo negociaciones } 5+2 \\
\uparrow \text { Crecimiento PIB } \\
\uparrow \text { Reducción déficit presupuestario } \\
\downarrow \text { No progreso significante en reducción de la pobreza ni en } \\
\text { desarrollo sostenible } \\
\uparrow \text { Preferencias comerciales } \\
\uparrow \text { Entorno empresarial } \\
\uparrow \text { Lucha contra blanqueo de dinero } \\
\uparrow \text { Derechos de propiedad } \\
\uparrow \text { Cooperación policial y judicial } \\
\uparrow \text { Transporte interno }\end{array}$ & $\begin{array}{l}\downarrow \text { Elecciones generales } \\
\uparrow \text { Derecho de las minorías } \\
\uparrow \text { Prevención de la tortura y mal trato en prisiones } \\
\uparrow \text { Sistema judicial y su acceso } \\
\uparrow / \downarrow \text { Resolución conflictos } \\
\uparrow / \downarrow \text { Control migraciones y derechos de los } \\
\quad \text { desplazados internos } \\
\uparrow \text { Crecimiento PIB, 2007: } 12 \% \\
\uparrow \text { Déficit comercial } \\
\uparrow \text { Comercio con UE (29,2\% del comercio exterior de } \\
\quad \text { Georgia) } \\
\uparrow \text { Entorno empresarial } \\
\uparrow \text { Recaudación impuestos } \\
\uparrow \text { Cooperación energética }\end{array}$ \\
\hline \multirow[b]{2}{*}{$\begin{array}{l}\text { Cumbre de Praga, } 2009 \\
\text { (Asociación Oriental) }\end{array}$} & \multicolumn{2}{|c|}{ Lanzamiento de la Asociación Oriental bajo los principios de diferenciación y condicionalidad. } \\
\hline & \multicolumn{2}{|c|}{$\begin{array}{l}\text { Acelerar cooperación multilateral a nivel regional y cooperación política e integración económica a nivel bilateral, a través } \\
\text { de un Acuerdo de Asociación. }\end{array}$} \\
\hline \multirow{2}{*}{ PIN 2011-2013 } & 273,14 millones de EUR & 180,29 millones de EUR \\
\hline & \multicolumn{2}{|l|}{$1 / 3$ destinado a promover democracia y Estado de Derecho } \\
\hline \multirow{4}{*}{ 2a Reforma, 2011} & \multicolumn{2}{|c|}{ Destaca la importancia de cooperar con el vecindario para acabar con amenazas que afectan a las nueva frontera de la UE. } \\
\hline & \multicolumn{2}{|c|}{ Resultados limitados hasta ahora: la UE necesita mayor coordinación con Estados miembros y Estados socios. } \\
\hline & \multicolumn{2}{|c|}{ Beneficios mutuos a través de la condicionalidad de respetar el Derecho de Estado y del rendimiento de cuentas mutuo. } \\
\hline & \multicolumn{2}{|c|}{$\begin{array}{l}\text { Nuevo enfoque: } \\
\text { (1) aumentar compromiso en la construcción de democracias consolidadas, } \\
\text { (2) incrementar integración económica para el desarrollo; y } \\
\text { (3) reforzar la Asociación Oriental y la otra asociación regional con el Mediterráneo. }\end{array}$} \\
\hline \multirow[t]{2}{*}{$\begin{array}{l}\text { Cumbre de Varsovia, } 2011 \\
\text { (Asociación Oriental) }\end{array}$} & \multicolumn{2}{|c|}{ Progreso en la promoción de movilidad y negociaciones para un Acuerdo de Asociación con Moldavia y Georgia. } \\
\hline & \multicolumn{2}{|l|}{ Evoluciones destacables } \\
\hline Informes de progreso en 2012 (2013) & $\begin{array}{l}\downarrow \text { Estabilidad política } \\
\uparrow \text { Sistema judicial y lucha contra corrupción } \\
\downarrow \text { Prevención de la tortura y mal trato en prisiones } \\
\uparrow / \downarrow \text { Libertad de expresión: reforma, pero prohibición de ciertos } \\
\text { símbolos comunistas } \\
\uparrow \text { Leyes contra discriminación y para la protección de minorías } \\
\uparrow \text { Participación en EUBAM y negociaciones } 5+2 \\
\downarrow \text { Crecimiento PIB en } 2012 \text { : } \\
-0,1 \%(2011:+6,8 \%) \\
\uparrow \text { Comercio con la UE (50\% del comercio exterior de Moldavia) } \\
\uparrow \text { VLAP }\end{array}$ & $\begin{array}{l}\downarrow \text { Elecciones parlamentarias } \\
\uparrow \text { Justicia selectiva } \\
\uparrow \text { Lucha contra la corrupción } \\
\uparrow \text { Detenciones sin juicio } \\
\uparrow \text { Libertad de asociación } \\
\uparrow / \downarrow \text { Representación y discriminación de minorías } \\
\downarrow \text { Relaciones con Abjasia } \\
\uparrow \text { Reducción desempleo } \\
\uparrow / \downarrow \text { Crecimiento PIB en 2012: 6,1\% (2011: 7\%) } \\
\uparrow \text { Déficit de cuenta corriente } \\
\uparrow \text { Entorno empresarial } \\
\uparrow \text { Servicios financieros }\end{array}$ \\
\hline $\begin{array}{l}\text { Cumbre de Vilnius, } 2013 \\
\text { (Asociación Oriental) }\end{array}$ & $\begin{array}{l}\text { Acuerdo de Asociación junto con DCFTA (firmado el } 27 \text { de junio de } \\
\text { 2014) }\end{array}$ & $\begin{array}{l}\text { Acuerdo de Asociación junto con DCFTA (firmado el } 27 \\
\text { de junio de 2014) }\end{array}$ \\
\hline Liberalización de visados & Aprobado por el Parlamento Europeo en febrero de 2014 & VLPA presentado en febrero de 2013 \\
\hline IEV 2014-2020 & \multicolumn{2}{|l|}{ General $=15.433$ millones de EUR } \\
\hline $\begin{array}{l}\text { Cumbre de Riga, } 2015 . \\
\text { (Asociación Oriental) }\end{array}$ & \multicolumn{2}{|c|}{$\begin{array}{l}\text { Implementación de los Acuerdo de Asociación y DCFTA como prioridades principales e importancia de disminuir la escalada } \\
\text { de violencia en el vecindario este. }\end{array}$} \\
\hline
\end{tabular}

5 Durante el primer semestre de 2007, el crecimiento del PIB era de un 8\%, aunque debido a una sequía, el crecimiento total del ejercicio fue positivo, 4,8\%, pero inferior al de 2006 (Comisión Europea, 2008b, p. 7).

6 Entre 2006 y 2007, las exportaciones de Moldavia a la UE aumentaron asombrosamente un 40,8\% (Comisión Europea, 2008b, p. 8). 
Como se puede observar en la tabla, desde su creación la PEV no ha cesado de evolucionar y de especializarse manteniendo los conceptos de condicionalidad positiva, diferenciación y titularidad compartida. Asimismo, podemos ver cómo en los Planes de Acción se prioriza entre otras cosas los conflictos secesionistas, lo que es coherente con el hecho de que la UE quiera aumentar la estabilidad y seguridad de su vecindario, como bien argumenta la Estrategia Europea de Seguridad del Consejo Europeo (2003). Pero dicha prioridad no se refleja en los presupuestos de la PEV. Como hemos destacado, el primer Programa Indicativo Nacional (PIN) se centraba en la reducción de la pobreza y el segundo, iba enfocado hacia reformas para fortalecer el Estado de derecho.

Otro aspecto destacable es la inclusión de Rusia en el documento Wider Europe de la Comisión Europea (2003) aunque finalmente no se incluyó en el Documento de Estrategia de la Comisión Europea (2004) manteniéndose así sus relaciones bilaterales fuera de este marco institucional. Otro cambio que llama la atención es que los tres países del Cáucaso Sur no estaban incluidos en el documento Wider Europe (2003). Sin embargo, un año más tarde, tras la publicación de la Estrategia Europea de Seguridad, que expresaba su preocupación por los conflictos próximos a las fronteras de la UE, el Documento de Estrategia (2004) incluyó la región del Cáucaso Sur en su política. Pero la UE tampoco se involucra realmente en sus conflictos, por lo que la verdadera razón por la cual han decidido incluir la región podría ser más bien por intereses energéticos. Después de todo, la Estrategia Europea de Seguridad también destaca su preocupación por la seguridad energética.

No obstante, aunque la UE no le ponga un remedio eficaz, la seguridad en general no deja de ser una preocupación para la Unión. Tras la guerra de 2008, no podemos hablar de conflictos congelados y la UE necesita estar cada vez más presente en el terreno si no quiere presenciar otra guerra. Además, es necesario que la UE sea consciente de la gran diferencia que existe entre el conflicto en Moldavia, de carácter económico-político, y los dos conflictos en Georgia, de carácter étnico (Popescu, 2005). Asímismo, Transnistria no ha sido reconocido como Estado por parte de Rusia, mientras que Abjasia y Osetia del Sur fueron reconocidos tras la guerra de $2008^{7}$.

Sin embargo, aunque la PEV no se haya realmente involucrado en los conflictos congelados, esta política ha tenido un impacto en la sociedad moldava y georgiana como podemos ver en los dos informes de progreso que se han seleccionado (2008 y 2013). De hecho, el cambio político pro-europeo de Moldavia coincidió con el lanzamiento de la Asociación Oriental, lo que probablemente haya sido un factor crucial para potenciar sus relaciones. En efecto, tanto Moldavia como Georgia han atravesado un cambio de gobierno que, por un lado, significa algo bueno: la oposición ha llegado a ganar las elecciones; pero, por otro lado, ambos países están gobernados ahora mismo por coaliciones inestables al estar compuestas de partidos muy diversos o por partidos con una dirección política ambigua.

Igualmente, durante estos últimos años, Rusia no ha cesado de sentirse amenazada por la PEV y su Asociación Oriental. Previamente a la Cumbre de Vilnius, en noviembre de 2013, Rusia se aprovechó de su ventaja energética e importancia comercial para amenazar a los Estados socios y convencerles de no firmar el Acuerdo de Asociación, mientras que la UE solo puede ofrecer principios democráticos y una mayor integración en la UE (Dempsey, 2013). En el caso de Ucrania, el Acuerdo de Asociación que iba a firmar en la Cumbre de Vilnius no ofrecía suficientes beneficios inmediatos, además de que Rusia hubiera reprimido económicamente a

7 Ambos Estados de facto son reconocidos por Rusia, Venezuela, Nicaragua y Nauru. Previamente fueron reconocidos por Vanuatu y Tuvalu hasta 2013 y 2014 respectivamente (RFE/RL, 2014a).

\section{Desde su creación, la PEV no ha cesado de evolucionar y de especializarse manteniendo los conceptos de condicionalidad positiva, diferenciación y titularidad compartida}


Ucrania a través de embargos y cortes en el suministro de gas. Esto, junto con el hecho de que la UE se negó a negociar dicho acuerdo con la presencia de Rusia al tratarse de negociaciones bilaterales, hizo que en noviembre de 2013 se iniciase la actual crisis de Ucrania (Rizzi, 2013).

Aun así, la Cumbre de Vilnius tuvo algunos resultados positivos. En primer lugar, Moldavia y Georgia se comprometieron a firmar sus respectivos Acuerdos de Asociación, los cuales fueron ratificados por el parlamento moldavo y georgiano en julio de 2014 (EurActiv, 2014; RFE/RL, 2014b). Por ello, vistos los últimos acontecimientos en Ucrania — a pesar de que el nuevo gobierno finalmente también ratificase en septiembre de 2014 el Acuerdo de Asociación (Parlamento Europeo, 2014b)_, es muy probable que la PEV y su Asociación Oriental se aferren en los próximos años a Moldavia y Georgia, para así no perder la poca influencia y estabilidad que le queda a la UE en su vecindario oriental, aunque sería de extrañar que su política hacia los conflictos congelados cambie drásticamente en un futuro cercano.

Además, dichos acuerdos no solo son importantes para Moldavia y Georgia en lo que respecta a la cooperación política, también incluyen las DCFTA. Según un estudio de dos consultorías, Ecorys y Case (2012, pp. A13-14, B9-10), la DCFTA permitirá a Moldavia aumentar sus exportaciones en un $16 \%$ y, en el caso de Georgia, un 12\%. Esto demuestra que los incentivos de la PEV y de la Asociación Oriental no son tan bajos como muchos autores defienden. En el caso de Moldavia, en febrero de 2014, el Parlamento Europeo acordó un régimen de liberación de visados, lo que es un incentivo enorme si se tiene en cuenta que la economía del país depende de remesas, 24\% del PIB en 2012 (Izquierdo, 2014, p. 6). En cuanto a Georgia desde febrero de 2013, la UE ha estado desarrollando un Plan de Acción para la liberalización de visados (VLAP) con dicho Estado (Ditrych, 2013).

\section{Una perspectiva teórica}

Como ya se ha mencionado previamente, podría decirse que Rusia intenta mantener el statu quo de los países de facto de la región para prevenir a los Estados involucrados (en este caso, Moldavia y Georgia) de asociarse con Occidente (la UE y la OTAN), quienes durante las ampliaciones de los últimos años han ganado excesiva influencia, desde la perspectiva rusa, en la región del Mar Negro. Por tanto, se puede decir que Rusia ve la PEV como una política que busca un equilibrio de poder contra el Kremlin ${ }^{8}$.

En definitiva, como hemos podido ver a lo largo de este estudio, Rusia destaca por emplear el hard power a través de la presencia militar de tropas tanto en Transnistria como en las regiones separatistas de Georgia. Igualmente, el uso de la coerción económica para persuadir a Moldavia y Georgia de, por ejemplo, no firmar los Acuerdos de Asociación es también una muestra de que Rusia es una potencia asidua del hard power. Por otra parte, se puede decir que la UE representa a una potencia occidental centrada en el uso de soft power mediante el cual cree que puede transformar y cultivar a otras sociedades en los valores comunes de la Unión, siendo

8 Como el neorrealismo o realismo estructural defienden, dentro de la anarquía que supone la arena internacional existe un cierto orden. Este orden viene marcado por la distribución del poder y de los intereses de los Estados, los actores principales de la comunidad internacional, que con la intención de mantener el statu quo —una situación de relativa estabilidad - actúan siguiendo el concepto de equilibrio de poder. Es decir, los Estados se asocian o alían entre sí con el fin de hacer frente a otras potencias que puedan estar ganando cada vez más poder y, así, reequilibrar la estructura de la comunidad internacional. Asimismo, según el neorrealismo, a través de la cooperación, los Estados se preocupan más por las ganancias relativas, es decir, se centran principalmente en lo que pueda beneficiarles a ellos. Véase Powell, 1991; Waltz, 2000; Goldstein \& Pevehouse, 2011, pp. 42-47. 
así una potencia normativa, a través de reformas democráticas y liberales. No obstante, la UE debe compartir su influencia en la región con Rusia y es difícil combatir el hard power, que aporta resultados a corto plazo, a través del soft power, el cual conlleva más tiempo para alcanzar resultados sostenibles: el establecimiento de democracias liberales y la estabilidad de la región.

En efecto, la teoría de la paz democrática defiende que dos Estados democráticos, es decir, con una democracia liberal en funcionamiento, no participarán en una guerra entre sí (Owen, 1994). Por una democracia liberal nos referimos a una democracia consolidada donde no solo se celebran elecciones, sino donde también hay una separación de poderes y un poder judicial independiente, donde se respetan las libertades individuales y el pluralismo político, y donde existe un Estado de derecho y un control por parte de los civiles sobre los militares (Tarzi, 2007, p. 49). Por tanto, el fortalecimiento de democracias implicaría un vecindario mucho más seguro al haber menos probabilidad de que estallen conflictos armados en la región.

Sin embargo, el éxito limitado de la PEV es una muestra de que dicha política ha sido demasiado ambiciosa y que no ha contado con suficientes recursos. Y por recursos no se quiere hacer referencia a una escasa financiación, sino más bien a una falta de voluntad por parte de los Estados miembros de crear una política común y ambiciosa de carácter regional. Por tanto, podemos decir que por mucho que el modelo del neoliberalismo institucional ${ }^{9}$ haya funcionado para la creación y desarrollo de la UE como una organización supranacional sui géneris (Magnette, 2005, p. 190) que desafíe el concepto realista de que los Estados son los actores principales en las relaciones internacionales (Ataman, 2003), parece que su ampliación tiene límites (o que por lo menos necesita un pausa) y que hace que finalmente los intereses propios de cada Estado miembro prevalezcan sobre temas como la política exterior, un ámbito que suele simbolizar la soberanía nacional de cada Estado y que pocos querrán ceder.

En otras palabras, parece que el neoliberalismo institucional acaba cuando el neorrealismo aparece: los Estados no dejan de ser los actores principales de la arena internacional que, después de todo, velan primero por sus intereses (ganancias relativas) y, si eso, por los intereses comunes (ganancias absolutas) ${ }^{10}$. Esta conclusión puede hacer pensar que tal vez la UE sea una potencia de soft power no tanto porque crea en ello, sino más bien porque es más fácil ponerse de acuerdo para utilizar las armas diplomáticas que las armas en sí, aunque exista un interés común por mantener en Europa una seguridad económica y energética. Y es en este último aspecto donde probablemente residen las mayores discrepancias. La fuente de un conflicto es muchas veces la escasez de recursos y, actualmente, la escasez de fuentes energéticas. Por consiguiente, es comprensible que aquellos Estados miembros que energéticamente dependan más de Rusia no quieran enfadarla interviniendo en Moldavia. O que aquellos Estados miembros que tal vez puedan beneficiarse de nuevos gaseoductos en el Cáucaso Sur piensen que es mejor intervenir en Georgia, ya que no afecta negativamente a sus intereses energéticos. La diversidad de Estados miembros ha hecho que los intereses sean a veces difícilmente reconciliables y, por tanto, más Europa podría significar una Europa más grande pero menos ambiciosa y profunda en lo relativo al alcance de sus políticas.

9 El neoliberalismo institucional se basa en la promoción de la cooperación a largo plazo —haciendo hincapié en las ganancias absolutas, por ejemplo, en la seguridad colectiva - y de las instituciones como forma de aumentar la seguridad regional, en el caso de la UE, e incluso internacional, en el caso del Consejo de Seguridad de las Naciones Unidas. Véase Powell, 1991; Keohane, 1998; Goldstein \& Pevenhouse, 201 1, pp. 65-69.

10 Véase notas al pie 8 y 9.

\section{Parece que el neoliberalismo institucional acaba cuando el neorrealismo aparece: los Estados no dejan de ser los actores principales de la arena internacional}




\section{Conclusiones}

Tras este estudio se puede deducir que la PEV surgió por una serie de circunstancias: una UE más extensa tras las ampliaciones de 2004 y 2007 y una Europa más reformista tras la Revolución Rosa de Georgia y la Revolución Naranja de Ucrania. Asimismo, la PEV nace prácticamente a la vez que la Estrategia Europea de Seguridad, en la cual se destaca la necesidad de un vecindario estable para una Europa segura. Cierto es que la PEV no ha tenido el mismo éxito en todos los Estados socios, aunque Moldavia y Georgia pueden considerarse como las dos grandes excepciones de este fiasco, tras realizar progresos considerables en sus sistemas políticos y economías, y tras decir el sí quiero a los Acuerdos de Asociación.

No obstante, la actuación de la PEV para resolver los conflictos de dichos países ha sido muy limitada. En efecto, a través de este trabajo se ha querido demostrar la influencia que ha tenido el Kremlin en suavizar los objetivos de la PEV. Es decir, con tal de no enfadar a la potencia energética, muchos Estados miembros han preferido no intervenir de más en Transnistria, Abjasia u Osetia del Sur. En el caso de Ucrania, el éxito de la PEV es aún muy limitado, su situación actual es aún demasiado inestable como para afirmar un éxito de la política en el país. Sin embargo, la UE debe aprender de sus limitaciones con Moldavia y Georgia para no cometer los mismos errores con Ucrania, tras la anexión de Crimea a Rusia y la secesión de facto de Donestk y Lugansk.

En definitiva, podemos dar por demostrada la hipótesis inicial: la PEV en el vecindario oriental ha logrado progresos en campos como el pluralismo político o la lucha contra la corrupción en Moldavia y Georgia. Sin embargo, no ha sido lo suficientemente eficaz ni coherente a la hora de intervenir en los conflictos secesionistas de estos dos Estados, debido a que los Estados miembros tienen diferentes intereses con Rusia lo que hace que una política exterior común sea difícilmente ambiciosa. En definitiva, habrá que esperar a ver cómo la nueva Alta Representante de la Unión para Asuntos Exteriores y Política de Seguridad, Federica Mogherini, y el nuevo Comisario de la PEV y Negociaciones para la Ampliación, Johannes Hahn, abordarán los antiguos y nuevos retos del vecindario oriental.

De momento, el Servicio Europeo de Acción Exterior y la Comisión han lanzado una consulta, abierta incluso a la sociedad civil, para valorar la PEV y así proponer al Consejo una lista de reformas para este otoño (Consejo de la UE, 2015a, pp. 8-9). Igualmente, la UE está en proceso de rediseño de la Estrategia Europea de Seguridad del 2003 para 2016 (Bendiek \& Kaim, 2015), queda pendiente ver si por fin la UE tendrá una posición clara y firme respecto a sus problemas con Rusia.

\section{Bibliografía}

Ataman, M. (2003, otoño). The Impact of Non-State Actor on World Politics: A Challenge to Nation-States. Alternatives: Turkish Journal of International Relations. Vol. 2(1), pp. 42-66.

Barbarosie, L. \& Coalson, R. (2014, 29 de septiembre). Empty pipeline Shows Difficulty Of Breaking Moldova's Gazprom Addiction. Radio Free Europe - Radio Liberty. Recuperado de http://www.rferl.org/content/moldova-romania-pipeline-gazprom-iasi-ungheni/2661 1594.html

Barbé, E. \& Johansson-Nogués, E. (2008). The EU as a modest "force for good": the European neighbourhood Policy. International Affairs. $N^{0} 84$ (I), pp. 81-96.
LA PEV en el vecindario oriental ha logrado progresos en campos como el pluralismo político - la lucha contra la corrupción en Moldavia y Georgia 
Bendiek, A. \& Kaim, M. (2015, junio). New European Security Strategy - The Transatlantic Factor. Stiftung Wissenschaft und Politik Comments, n ${ }^{\circ} 34$.

Boonstra, J. \& Shapovalova N. (2010, mayo). La Asociación Oriental de la Unión Europea: Un año de retrocesos. FRIDE Documento de trabajo. $N^{o}$ 99. Recuperado de http://www. fride.org/descarga/WP_Asociacion_Oriental_ESP_May10.pdf

Călugăreanu, V. (2015, 29 de julio). Valeriu Strelet: "Sunt loial partidului!". Deutsche Welle. Recuperado de: http://dw.com/p/1G6uZ

Cámara, M. de la. (2008, enero). Las Relaciones entre la Unión Europea y Rusia. UNISCI Discussion Papers. $N^{\circ}$ 16, pp. 85-110.

Coalson, R. (2014, 23 de septiembre). Spat Over Who Speaks at UN Hints Of Looming Political Crisis In Georgia. Radio Free Europe - Radio Liberty. Recuperado de http://www.rferl. org/content/georgia-garibashvili-margvelashvili-ivanishvili-political-crisis/26602307. html

Comisión Europea y Alto Representante de la Unión Europea para Asuntos Exteriores y Política de Seguridad. (2011, 25 de mayo). A New Response to a Changing Neighbourhood: A review of European Neighbourhood Policy. Bruselas, COM(2011) 303.

Comisión Europea y Alto Representante de la Unión Europea para Asuntos Exteriores y Política de Seguridad. (2013a, 20 de marzo). Implementation of the European Neighbourhood Policy in Georgia Progress in 2012 and recommendations for action. Joint Staff Working Document, Bruselas, SWD(2013) 90 final.

Comisión Europea y Alto Representante de la Unión Europea para Asuntos Exteriores y Política de Seguridad. (2013b, 20 de marzo). Implementation of the European Neighbourhood Policy in Moldova Progress in 2012 and recommendations for action. Joint Staff Working Document, Bruselas, SWD(2013) 80 final.

Comisión Europea y Dirección General de Relaciones Exteriores. (2007a). European Neighbourhood and Partnership Instrument. Georgia: National Indicative Programme 2007-2010. Recuperado de http://eeas.europa.eu/enp/pdf/pdf/country/enpi_csp_nip_georgia_en.pdf

Comisión Europea y Dirección General de Relaciones Exteriores. (2007b). European Neighbourhood and Partnership Instrument. Moldova: National Indicative Programme 2007-2010. Recuperado de http://ec.europa.eu/world/enp/pdf/country/enpi_nip_moldova_en.pdf

Comisión Europea y Dirección General de Relaciones Externas. (2010a). European Neighbourhood and Partnership Instrument. Georgia: National Indicative Programme 2011-2013. Recuperado de http://ec.europa.eu/world/enp/pdf/country/2011_enpi_nip _georgia_en.pdf

Comisión Europea y Dirección General de Relaciones Externas. (2010b). European Neighbourhood and Partnership Instrument. Moldova: National Indicative Programme 2011-2013. Recuperado de http://ec.europa.eu/world/enp/pdf/country/2011_enp_nip_moldova_en.pdf

Comisión Europea. (2003, 11 de marzo). Wider Europe - Neighbourhood: A New Framework for Relations with our Eastern and Southern Neighbours. Bruselas, COM(2003) 104 final.

Comisión Europea. (2004, 12 de mayo). European Neighbourhood Policy: Strategy Paper. Bruselas, $\operatorname{COM}(2004) 373$ final. 
Comisión Europea. (2005). EU/Moldova Action Plan. Recuperado de http://eeas.europa.eu/ enp/pdf/pdf/action_plans/moldova_enp_ap_final_en.pdf

Comisión Europea. (2006a). EU/Georgia Action Plan. Recuperado de http://eeas.europa.eu/ enp/pdf/pdf/action_plans/georgia_enp_ap_final_en.pdf

Comisión Europea. (2006b, 4 de diciembre). On Strengthening the European Neihbourhood Policy. Bruselas, COM(2006) 726 final.

Comisión Europea. (2008a, 3 de abril). Implementation of the European Neighbour-hood Policy in 2007. Progress Report Georgia. Joint Staff Working Document, Bruselas, SEC(2008) 393.

Comisión Europea. (2008b, 3 de abril). Implementation of the European Neighbour-hood Policy in 2007. Progress Report Moldova. Joint Staff Working Document, Bruselas, SEC(2008) 399.

Comisión Europea. (2011, 25 de mayo). A new ambitious European Neighbourhood Policy. European Commission Press Release database. IP/11/643.

Comisión Europea. (2013a, 27 de agosto). Comissioner Oettinger inaugurates the Works of Romanian-Moldovian gas pipeline. European Commission Press Release Database. Bruselas, IP/13/792.

Comisión Europea. (2013b, 15 de noviembre). First Progress Report on the implementation by Georgia of the Action Plan on Visa Liberalisation. Bruselas, COM(2013) 808 final.

Comisión Europea. (2013c, 2 de diciembre). Georgia and Moldova one step closer to enhanced political and trade relations with the EU. European Commission Press Release Database. MEMO/13/1078.

Comisión Europea. (2013d, 11 de diciembre). The Multiannual Financial Framework: The External Action Financing Instruments. European Commission Press Release Database. Bruselas, MEMO/13/1134.

Comisión Europea. (2014, 27 de junio). Remarks by President Barroso at the signing of the Association Agreements with Georgia, the Republic of Moldova and Ukraine. Europa Press Release Database. Bruselas, SPEECH/14/511.

Consejo de la Unión Europea. (2009, 7 de mayo). Joint Declaration of the Prague Eastern Partnership Summit. Bruselas, 8435/09 (PRESSE 78).

Consejo de la Unión Europea. (2011, 30 de septiembre). Joint Declaration of the Eastern Partnership Summit. Varsovia, 14983/11 (PRESSE 341).

Consejo de la Unión Europea. (2013, 29 de noviembre). Joint Declaration of the Eastern Partnership Summit. Vilnius, 17130/13 (PRESSE 516).

Consejo Europeo. (2003, 12 de diciembre). Una Europa segura en un mundo mejor: Estrategia Europea de Seguridad, Bruselas. Recuperado de http://www.consilium.europa.eu/ uedocs/cmsUpload/031208ESSIIES.pdf

Consejo de la Unión Europea (2015a, 20 de abril). Outcome of the 3382nd Council meeting. Foreign Affairs. Luxemburgo, 8084/15 (PRESSE 27).

Consejo de la Unión Europea (2015b, mayo). Joint Declaration of the Eastern Partnership Summit (Riga, 21-22 May 2015). 
Coppieters, B. (2007, diciembre). The EU and Georgia: time perspectives in conflict resolution. EU Institute for Security Studies Occasional Paper. No 70. Recuperado de http:// www.iss.europa.eu/uploads/media/occ70.pdf

Dannreuther, R. (2006). Developing the Alternative to Enlargement: The European Neighbourhood Policy. European Foreign Affairs Review. Nº11, pp. 183-201.

Dempsey, J. (2013, 9 de septiembre). How Russia Bullies the EU's Eastern Neighbors. Carnegie Europe. Recuperado de http://carnegieeurope.eu/strategiceurope/?fa= 52903

Ditrych, O. (2013, julio). The Georgian succession. EU Institute for Security Studies Brief. $N^{o}$ 26. Recuperado de http://www.iss.europa.eu/uploads/media/Brief_26.pdf

Dreyfus, E. (2009, 28 de julio). La Moldavie au bord de l'écartèlement identitaire. Le Monde diplomatique. Recuperado de http://blog.mondediplo.net/2009-07-28-La-Moldavie-aubord-de-l-ecartelement-identitaire

Ecorys, Case. (2012, 27 de octubre). Trade Sustainability Impact Assessment in support of negotiations of a DCFTA between the EU and Georgia and the Republic of Moldova. Informe realizado bajo la petición de la Comisión Europea. Recuperado de http://trade.ec.europa. eu/doclib/docs/2012/november/tradoc_150105.pdf

EurActiv. (2014, 2 de julio). Moldova sets record in ratifying EU association agreement. EurActiv. Recuperado de http://www.euractiv.com/sections/europes-east/moldova-sets-recordratifying-eu-association-agreement-303249

European Union Institute for Security Studies [EU ISS]. (2013, marzo). Moldova's political crisis. EU Institute for Security Studies Alert. $N^{o}$ 1. Recuperado de http://www.iss.europa. eu/uploads/media/Alert_Moldova.pdf

Fischer, S. (2010, diciembre). The EU, Russia and the neighbourhood. EU Institute for Security Studies Analysis. Recuperado de http://www.iss.europa.eu/uploads/media/The_EU_Russia_and_the_neighbourhood.pdf

Freire, M. R. \& Simao, L. (2013, junio). The EU in Georgia: Building Security? Oficina do CES. No 396. Recuperado de http://www.ces.uc.pt/myces/UserFiles/livros/1097_7612_ Oficina_do_CES_396.pdf

Goldstein, J. S. \& Pevehouse, J. C. (2011). International Relations. Pearson, 6 a edición breve.

Haukkala, H. (2008, noviembre). The European Union as a Regional Normative Hegemon: The Case of European Neighbourhood Policy. Europe-Asia Studies. Vol. 60(9), pp. 1601-1622.

Herranz Surallés, A. (2007). La Política Europea de Vecindad (PEV): ¿Un nuevo modelo de gobernanza exterior? Anuario Internacional CIDOB 2006: Claves para interpretar la Politica Exterior Española y las Relaciones Internacionales en 2006, edición de 2007, pp. 268-275.

Huff, A. (2011, mayo). The role of EU defence policy in the Eastern neighbourhood. EU Institute of Security Studies Occasional Paper. No 91. Recuperado de http://www.iss.europa.eu/uploads/ media/op91-The_role_of_EU_defence_policy_in_the_Eastern_neighbourhood.pdf

International Crisis Group. (2007, 7 de junio). Georgia’s South Ossetia Conflict: Make Haste Slowly. Europe Report. No 183. http://www.crisisgroup.org/ /media/Files/europe/183_ georgia_s_south_ossetia_conflict_make_haste_slowly.ashx 
Izquierdo Alberca, M. J. (2014, 5 de marzo). Moldavia: desafíos y esperanzas. IEEE Documento informativo. $N^{o}$ 04/2014. Recuperado de http://www.ieee.es/Galerias/fichero/docs_informativos/2014/DIEEEI04-2014_Moldavia_Esperanzas-Desafios_MJIA.pdf

Jégo, M. (2014). L'atlas de 193 pays: Géorgie. Le Monde: Le bilan du monde 2014 (Hors-Série), p. 130 .

Keohane, R. O. (1998, primavera). International Institutions: Can Interdependence Work? Foreign Policy. $N^{o} 110$, pp. 82-96.

Kleenmann, K. (2010). The European Neighbourhood Policy - A Reality Check: How effective is the European Neighbourhood Policy in promoting good governance? Romanian Journal of Political Science. Vol. 10(2), pp. 118-143.

Kvashuk, O., Solonenko, I. \& Ursu, V. (Eds.). (2013). European Integration Index 2013 for Eastern Partnership Countries. Informe realizado por International Renaissance Foundation, Open Society Foundations y Eastern Partnership Civil Society Forum. Recuperado de http://www.eap-index.eu/sites/default/files/EaP_Index_2013.pdf

Leonard, M. \& Grant, C. (2005, septiembre). Georgia and the EU: Can Europe's neighbourhhod policy deliver? Centre for European Reform Policy Brief. Recuperado de http://www. cer.org.uk/sites/default/files/publications/attachments/pdf/2011/policybrief_georgia_ sept05-833.pdf

Leonard, P. (2015, 7 de agosto). Kyrgyzstan Joins Eurasian Union, Takes Leap Into the Dark. EurasiaNet.org. Recuperado de http://www.eurasianet.org/node/74591

Lovitt, J. (ed.). (2015, febrero). European Integration Index 2014 for Eastern Partnership Countries. Informe realizado por International Renaissance Foundation, Open Society Foundations, Policy Association for an Open Society y Eastern Partnership Civil Society Forum. Recuperado de http://www.eap-index.eu/sites/default/files/EaP\%20Index\%202014.pdf

Lynch, D. (2006, febrero). Why Georgia matters? EU Institute for Security Studies Chaillot Paper. $N^{\circ}$ 86. Recuperado de http://www.iss.europa.eu/uploads/media/cp086.pdf

Magnette, P. (2005). What is the European Union: Nature and prospects. Hampshire, New York: Palgrave Macmillan.

Manners, I. (2002). Normative Power Europe: A Contradiction in Terms? Journal of Common Market Studies, vol. 40, nº 2, pp. 235-258.

Martín, I. (2012). ¿Qué finalité politique para la Política Europea de Vecindad? Sobre los objetivos e instrumentos de la cooperación de la UE con sus países vecinos. Anuario Jurídico y Económico Escurialense. XLV, pp. 359-388.

Moldpres. (2015a, 6 de enero). Energy Regulation Agency issues licence to company transporting gas via Moldovan-Romanian pipeline. Moldova's State News Agency. Recuperado de http://www.moldpres.md/en/news/2015/01/06/15000068

Moldpres. (2015b, 4 de marzo). Moldova starts gas imports from Romania through Iasi-Ungheni pipeline. Moldova's State News Agency. Recuperado de http://www.moldpres.md/en/ news/2015/03/04/15001422

Niemann, A. \& Wekker, T. (2010). Normative power Europe? EU relations with Moldova. European Integration Online Papers. Vol. 14, art. 14. 
Nye, J. S. (2011). The Future of Power. New York: Public Affairs.

O’Neill, L. (2009, 4 de diciembre). Moldova - the Switzerland solution? Open Democracy. Recuperado de http://www.opendemocracy.net/od-russia/louis-oneill/moldova-switzerland-solution

Owen, J. M. (1994, otoño). How Liberalism Produces Democratic Peace. International Security. Vol. 19(2), pp. 87-125.

Parlamento Europeo y Consejo de la Unión Europa. (2006, 9 de noviembre). Regulation (EC) $N^{\circ} 1638 / 2006$ of the European Parliament and of the Council of 24 October 2006 laying down general provisions establishing a European Neighbourhood and Partnership Instrument. Official Journal of the European Union. L 310/13.

Parlamento Europeo. (2014a, 27 de febrero). Parliament gives green light to visa-free travel for Moldovan citizens. European Parliament Press Release.

Parlamento Europeo. (2014b, 16 de septiembre). European Parliament ratifies EU-Ukraine Association Agreement. European Parliament Press Release.

Pop, I. (2009, marzo). The Assessment of the European Neighbourhood Policy in the South Caucasus: What the European Union can do? Eurolimes. Vol. 7, pp. 22-34.

Popescu, A. (2011). European Neighbourhood Policy and the Georgian-Abkhaz Conflict: European Union's Approach. Anelele Universitatii din Oradea, Seria Relatii Intenationale su Studii Europene, tomo III, pp. 188-195.

Popescu, N. (2005, octubre). The EU in Moldova - Settling conflicts in the neighbourhood. EU Institute for Security Studies Occasional Paper. No 6. Recuperado de http://www.iss. europa.eu/uploads/media/occ60.pdf

Popescu, N. (2007, marzo). Europe's Unrecognised Neighbourhoods: The EU in Abkhazia and South Ossetia. CEPS Working Documents. $N^{\circ}$ 260. Recuperado de http://aei.pitt. edu/7384/2/7384.pdf

Popescu, N. (2014, mayo). Ukraine: four crises, one country. EU Institute for International Security Studies Brief Issue. $N^{o}$ 16. Recuperado de http://www.iss.europa.eu/uploads/ media/Brief_16_Ukraine_crisis.pdf

Powell, R. (1991, diciembre). Absolute and Relative Gains in International Relations Theory. The American Political Science Review. Vol. 85(4), pp. 1303-1320.

Radio Free Europe - Radio Liberty [RFE/RL]. (2014a, 25 de abril). Tuvalu Retracts Recognition of Abkhazia, South Ossetia. RFE/RL. Recuperado de http://www.rferl.org/content/ tuvalu-georgia-retracts-abkhazia-ossetia-recognition/ 25315720.html

Radio Free Europe - Radio Liberty [RFE/RL]. (2014b, 18 de julio). Georgia Ratifies EU Association Agreement. RFE/RL. Recuperado de http:/www.rferl.org/content/georgia-euassociation-agreement-ratification-parliament/25461441.html

Rizzi, A. (2013, 29 de noviembre). Rusia gana a la UE la batalla de Ucrania. El País. Recuperado de http://internacional.elpais.com/internacional/2013/11/29/actualidad/1385718375_978851. html

Sasse, G. (2008, marzo). The European Neighbourhood Policy: Conditionality Revisted for the EU's Eastern Neighbours. Europe-Asia Studies. Vol. 60(2), pp. 295-316. 
Solash, R. (2013, 20 de septiembre). Moldovan Foreign Minister Says Country 'Strong Enough' To Resist Russian Pressure. RFE/RL. Recuperado de http://www.rferl.org/content/moldova-eastern-partnership-gherman-russia-wine-ban-eu/25112919.html

Soler i Lecha, E. \& Viilup, E. (2011, junio). Revisando la Política Europea de Vecindad: Respuesta débil a rápido cambios. Notes internacionals CIDOB. $N^{\circ} 36$.

Tarzi, S. M. (2007, diciembre). Democratic Peace, Illiberal Democracy, and Conflict Behavior. International Journal on World Peace. Vol. XXIV(4), pp. 35-60.

The Economist. (2010, 31 de marzo). Poor Moldova: Chisinau's charm offensive. The Economist. Recuperado de http://www.economist.com/node/15825734

The Economist. (2014, 6 de diciembre). Slouching towards Europe: Pro-Russia parties lose a close vote in a corrupt land. The Economist. Recuperado de http://www.economist.com/ node/21635508

Trifon, N. (2013, septiembre-octubre). République de Moldavie en 2013: Entre l'Europe et l'Eurasie. Diplomatie. $N^{0}$ 64, pp. 12-16.

Ursu, V. \& Coalson, R. (2015, 20 de febrero). Moldova's Creaking Political System Could Be A Gift For Moscow. RFE/RL. Recuperado de http://www.rferl.org/content/moldovapolitical-dysfunction-gift-for-moscow/26860292.html

Ventila, C. D. (2010, 12 de abril). Moldavia: ¿hacia un nuevo giro político? ARI (Real Instituto Elcano). $N^{o}$ 67. Recuperado de http://www.realinstitutoelcano.org/wps/portal/rielcano/ contenido?WCM_GLOBAL_CONTEXT=/elcano/elcano_es/zonas_es/europa/ari672010

Waltz, K. N. (2000, verano). Structural Realism after the Cold War. International Security. Vol. 25(1), pp. 5-41.

Wilson, A. \& Popescu, N. (2009, septiembre). Russian and European neighbourhood policies compared. Southeast European and Black Sea Studies. Vol. 9(3), pp. 317-331.

Wolff, S. (2012, 26 de octubre). The Transnistrian Issue: Moving Beyond the Status-quo. Policy Department DG External Policies. Recuperado de https://www.gov.uk/government/ uploads/system/uploads/attachment_data/file/224472/evidence-stefan-wolff-the-transnistrian-issue.pdf

Zagorski, A. (2012, 14 de febrero). Russia's neighbourhood policy. EU Institute for Security Studies. Recuperado de http://www.iss.europa.eu/publications/detail/article/ russiasneighbourhood-policy

Zhemukhov, S. (2012, 12 de septiembre). Does Abkhazia need a foreign policy makeover? OpenDemocracy. Recuperado de http://www.opendemocracy.net/od-russia/sufian-zhemukhov/does-abkhazia-need-foreign-policy-makeover 